\title{
Efficiency of Fluid Treatments with Different Sodium Concentration in Children with Type 1 Diabetic Ketoacidosis
}

\author{
Şenay Savaş-Erdeve1, Merih Berberoğlu1, Pembe Oygar1, Zeynep Şıklar1, Tanıl Kendirli2, \\ Bülent Hacıhamdioğlu1, Pelin Bilir1, Gönül Öçal1 \\ ${ }^{1}$ Ankara University School of Medicine, Department of Pediatrics, Division of Pediatric Endocrinology, Ankara, Turkey \\ ${ }^{2}$ Ankara University School of Medicine, Department of Pediatrics, Pediatric Intensive Care Unit, Ankara, Turkey
}

\begin{abstract}
Objective: The management of children with diabetic ketoacidosis (DKA) continues to be a controversial issue with regard to amount of intravenous fluid to be given, rate of delivery of fluid, and type of fluid to be used. We aimed to analyze the results obtained by administration of rehydration fluids of two different sodium ( $\mathrm{Na}$ ) concentrations $(75$ $\mathrm{mEq} / \mathrm{L}$ vs. $100 \mathrm{mEq} / \mathrm{L}$ ) in the treatment of children with DKA.

Methods: Thirty-two children with DKA were assessed for efficacy and safety of fluid treatment. After an initial rehydration time, intravenous fluids were switched to a $5 \%$ dextrose solution with a Na content of 75 $\mathrm{mEq} / \mathrm{L}$ (Group I, $\mathrm{n=19}$ ) or $100 \mathrm{mEq} / \mathrm{L}$ (Group II, $\mathrm{n}=13$ ). Venous blood samples were collected from all subjects at diagnosis and at the $4^{\text {th }}, 8^{\text {th }}, 16^{\text {th }}$ and $24^{\text {th }}$ hours of treatment.

Results: Changes in blood glucose levels did not differ significantly between the two groups at the $4^{\text {th }}, 8^{\text {th }} 16^{\text {th }}$ and $24^{\text {th }}$ hours of the follow-up. Nadir effective plasma osmolality (Peff osm) and Peff osm levels also did not show statistically significant differences. Plasma sodium $\left(\mathrm{P}_{\mathrm{Na}}\right.$ ) level did not drop lower than the level at diagnosis in both groups. The changes in $\mathrm{P}_{\mathrm{Na}}$ concentrations in the two groups were not statistically significant at diagnosis or in follow-up samples $(\mathrm{p}=0.74)$. $\mathrm{pH}$, anion gap, $\mathrm{pCO}_{2}$ and $\mathrm{HCO}_{3}$ levels were also similar in Group I and Group II. The duration of a pH level of $<7.3$ was shorter in Group II, but this was not statistically significant $(p=0.65)$. None of the patients enrolled in this study developed cerebral edema.

Conclusion: The efficacy and safety of rehydration fluids with $\mathrm{Na}$ concentrations of 75 or $100 \mathrm{mEq} / \mathrm{L}$ did not reveal any differences in children with DKA.

Key words: Diabetic ketoacidosis, sodium concentration, rehydration fluid, effective plasma osmolality
\end{abstract}

Conflict of interest: None declared

Received: 06.03.2011

Accepted: 14.05.2011

\section{Introduction}

Diabetic ketoacidosis (DKA) in children is a serious acute complication of diabetes mellitus and continues to be an important cause of morbidity and mortality. Treatment of children with DKA is a complex blend of emergency therapy and underlying disease management (1). Immediate but cautious fluid therapy is an essential component in the management of patients with DKA. The European Society for Paediatric Endocrinology (ESPE) and other international consensus recommendations have emphasized the importance of appropriate sodium ( $\mathrm{Na}$ ) concentration in the rehydration solutions used in treatment of DKA $(2,3,4,5)$. Initially, $0.9 \%$ isotonic salt solution ([Na]= $154 \mathrm{mEq} / \mathrm{L})$ has been considered the most suitable parenteral solution to initiate rehydration for the first hour or in the first 4 hours, depending on different authors, and thereafter is switched to a solution of lower tonicity $(\geq 0.45 \%$ saline solution; ([Na] $\geq 77 \mathrm{mEq} / \mathrm{L})$ until complete rehydration $(2,3,4,5)$. However, there continues to be a debate about the amount of intravenous (IV) fluid to be given, the speed of delivery of fluid, and the type of fluid to be used. Because a $0.45 \%$ saline solution is not available in Turkey, treatment of DKA patients is initiated with $0.9 \% \mathrm{Na}$ saline and continued by a mixture of $5 \%$ dextrose and $0.9 \% \mathrm{Na}$ saline. In the past, a solution with a $\mathrm{Na}$ concentration of $75 \mathrm{mEq} / \mathrm{L}$ has been

\section{Address for Correspondence}

Şenay Savaş-Erdeve MD, Ankara University School of Medicine, Department of Pediatrics, Division of Pediatric Endocrinology, Ankara, Turke GSM: +90 5054812150 E-mail: senaysavas@yahoo.com

(c) Journal of Clinical Research in Pediatric Endocrinology, Published by Galenos Publishing. 
used. However, in our clinic we observed that some patients developed low plasma sodium levels ( $\mathrm{P}_{\mathrm{Na}}$ ) (corrected plasma $\mathrm{Na}<130 \mathrm{mEq} / \mathrm{L}$ ) on the $8^{\text {th }}$ hour of treatment with this kind of approach. Considering that this treatment regimen might be a risk factor for development of cerebral edema (CE), we began to use a solution with a $\mathrm{Na}$ concentration of 100 $\mathrm{mEq} / \mathrm{L}$ in the treatment of our DKA patients.

In this study, we aimed to analyze the influence of two solutions with different $\mathrm{Na}$ concentrations in the rehydration of children with DKA.

\section{Material and Methods}

Patients who received an IV solution with a $\mathrm{Na}$ concentration of $75 \mathrm{mEq} / \mathrm{L}$ constituted Group I. This group consisted of patients who were treated before year 2006. Patients who received a solution with a $\mathrm{Na}$ concentration of $100 \mathrm{mEq} / \mathrm{L}$ constituted Group II. All data including age, sex, and new-onset diabetes were retrospectively collected from patient records. The study was approved by the local Ethics Committee.

This study included patients younger than 18 years of age who were admitted to the pediatric intensive care unit from 2002 to 2009. DKA was defined as having a glycemia $>200 \mathrm{mg} / \mathrm{dL}(11.4 \mathrm{mmol} / \mathrm{L})$, a venous $\mathrm{pH}<7.30$ or a plasma bicarbonate level $<15 \mathrm{mmol} / \mathrm{L}$, and ketonuria (2). Effective plasma osmolality ( $\mathrm{P}_{\text {eff osm }}$ ) was calculated as $2 \times \mathrm{P}_{\mathrm{Na}}+$ $P_{\text {Glucose }}$ (plasma glucose) in $\mathrm{mmol} / \mathrm{L}$ (6). $\mathrm{P}_{\mathrm{Na}}$ was corrected

\begin{tabular}{|c|c|c|c|}
\hline & Group I (n=19) & Group II (n=13) & p-value \\
\hline Age (years) & $8.7 \pm 4.1$ & $9.5 \pm 4$ & 0.579 \\
\hline Sex (female/male) & $11 / 8$ & $4 / 9$ & 0.166 \\
\hline PGlucose (mg/dL) & $533.7 \pm 246.4$ & $599.7 \pm 241.3$ & 0.27 \\
\hline $\mathrm{pH}$ & $7.17 \pm 0.15$ & $7.18 \pm 0.13$ & 0.73 \\
\hline $\mathrm{HCO}_{3}(\mathrm{mEq} / \mathrm{L})$ & $6.93 \pm 3.82$ & $6.61 \pm 3.99$ & 0.81 \\
\hline $\mathrm{pCO}_{2}$ & $17 \pm 6.3$ & $15.4 \pm 5.3$ & 0.46 \\
\hline Anion gap & $30.2 \pm 6.7$ & $32.1 \pm 9.9$ & 0.79 \\
\hline$P_{\text {eff osm }}(\mathrm{m} 0 \mathrm{sm} / \mathrm{L})$ & $293.2 \pm 9.4$ & $293.4 \pm 12.4$ & 0.80 \\
\hline $\mathrm{P}_{\mathrm{Na}} \quad(\mathrm{m} 0 \mathrm{sm} / \mathrm{L})$ & $132.2 \pm 7.4$ & $130.5 \pm 5.5$ & 0.89 \\
\hline $\mathrm{P}_{\text {Nacorr }}(\mathrm{m} 0 \mathrm{sm} / \mathrm{L})$ & $138.9 \pm 4.7$ & $138.2 \pm 5.5$ & 0.74 \\
\hline Hct $(\%)$ & $42.1 \pm 4.3$ & $42.1 \pm 3.6$ & 0.96 \\
\hline Leukocyte $\left(\mathrm{mm}^{3}\right)$ & $20.3 \pm 11.1$ & $20.6 \pm 13.6$ & 0.82 \\
\hline
\end{tabular}

for hyperglycemia using the method of Katz (7), whereby corrected plasma sodium ( $\mathrm{P}_{\text {Nacorr }}$ ) $(\mathrm{mmol} / \mathrm{L})=$ actual $\mathrm{Na}+$ [(serum glucose $\mathrm{mmol} / \mathrm{L}$ - 5.6)/5.6] x 1.6. Definition of cerebral edema (CE) was made according to the criteria defined by Edge et al (1).

In both groups, initial rehydration was performed with isotonic solutions in the first hour of treatment. The total volume to be given was calculated assuming a $10 \%$ deficit plus maintenance fluid. Amounts of fluids used in the initial resuscitation were subtracted from the total volume calculated for 48 hours and the infusion rate was adjusted accordingly. After initial rehydration, IV fluids were switched to solutions containing $5 \%$ dextrose and $[\mathrm{Na}+] 75$ $\mathrm{mEq} / \mathrm{L}$ (Group I) or [Na+] $100 \mathrm{mEq} / \mathrm{L}$ (Group II). The only source of $\mathrm{Na}$ used in our patients was $\mathrm{Na}$ chloride $(\mathrm{NaCl})$. The patients in Group I had received IV fluids with a $\mathrm{Na}$ concentration of $75 \mathrm{mEq} / \mathrm{L}(1 / 2$ isotonic $\mathrm{NaCl}$ plus $1 / 25 \%$ dextrose) and those in Group II received IV fluids with a $\mathrm{Na}$ concentration of $100 \mathrm{mEq} / \mathrm{L}(2 / 3$ isotonic $\mathrm{NaCl}$ plus $1 / 35 \%$ dextrose). During rehydration, the potassium concentration of the IV fluids was adjusted as $40 \mathrm{mEq} / \mathrm{L}$. The patients were started on oral intake and subcutaneous insulin as soon as the acidosis was resolved, serum $\mathrm{Na}$ level became stable, and vomiting had stopped. After transition to oral intake, the amount of oral fluid was subtracted from the ongoing IV fluid treatment.

Data on age, sex, date of onset and duration of diabetes at the time of diagnosis were recorded. Data pertaining to the same patient in different DKA episodes were recorded separately. After admission, blood glucose was measured at hourly intervals. Samples of venous blood for blood gases and electrolytes were taken at admission and at the $4^{\text {th }}, 8^{\text {th }}, 16^{\text {th }}$ and $24^{\text {th }}$ hours after admission.

The Mann-Whitney $U$ test was used to compare the clinical characteristics and laboratory values between the two groups. ANOVA test was used for variance analysis between groups. A p-value below 0.05 was accepted as significant.

\section{Results}

A total of 32 children who received DKA treatment were enrolled in the study. Twenty-six of these patients had new-onset diabetes. Group I included 19 patients and 13 patients were in Group II. None of the patients enrolled in this study developed CE. Clinical characteristics and biochemical data for the two groups at the time of admission are given in Table 1 .

The courses of glycemia and effective osmolality in our patients are shown in Figure 1 and Figure 2. Blood glucose 
levels after one hour of rehydration were not statistically different between groups $(424.1 \pm 223.3 \mathrm{mg} / \mathrm{dL}$ in Group I and $424 \pm 96 \mathrm{mg} / \mathrm{dL}$ in Group II) $(p=0.236)$. The most significant decrease in blood glucose was noted at the $4^{\text {th }}$ hour of treatment in both groups and the proportions of change (in percentages) in Group I and Group II were as $44.8 \pm 14 \%$ and $50.4 \pm 15 \%$, respectively. Time at which nadir blood glucose level was reached was the $8^{\text {th }}$ hour in Group I and the 16th hour in Group II. Proportion of change (in percentages) in blood glucose levels did not differ significantly between the groups at $4^{\text {th }}, 8^{\text {th }}, 16^{\text {th }}$ and $24^{\text {th }}$ hours.

Duration of insulin administration by IV infusion showed a significant difference between the groups, and was 5 (2-62) hours in Group I and 23 (2-74) hours in Group II $(p=0.018)$.

The median transition time to oral intake in Group I was 8 (4-62) hours. This period was shorter as compared to Group II [23 (3-74) hours] ( $p=0.033)$.

The $P_{\text {eff osm }}$ dropped during the first 8 hours of treatment in Group I, whereas in Group II, such fall occurred at the $16^{\text {th }}$ hour of therapy. Nadir Peff osm level was similar in Group I and Group II (Figure 2). The difference in

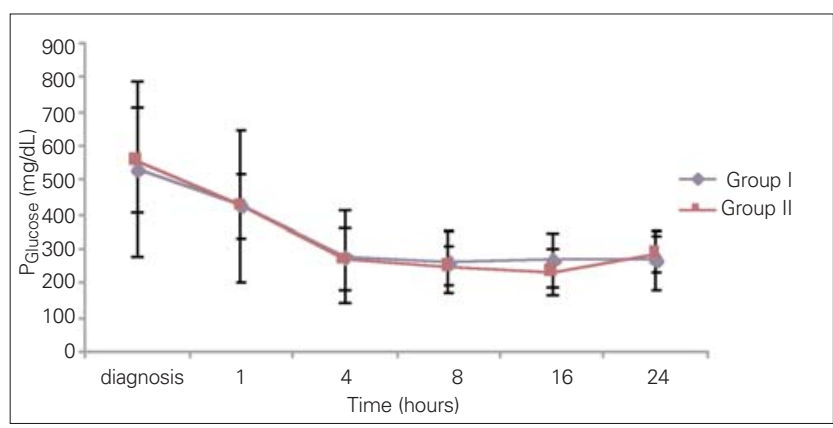

Figure 1. Time courses for $P_{\text {Glucose }}$ from the start of therapy up to 24 hours of therapy

$P_{\text {Glucose }}: \mathrm{mg} / \mathrm{dL}$
Peff osm between the two groups did not show statistical significance during follow-up $(p=0.80)$.

The course of natremia in our patients is shown in Figure 3. The $P_{\mathrm{Na}}$ level did not drop lower than the level at diagnosis in either group. Mean $\pm S D$ of $P_{N a}$ levels at diagnosis and during follow-up are shown in Table 2. The difference in $\mathrm{P}_{\mathrm{Na}}$ between Group I and Group II was not statistically significant at either the diagnosis or the $4^{\text {th }}, 8^{\text {th }}, 16^{\text {th }}$ and $24^{\text {th }}$ hours after diagnosis $(p=0.35)$. The rate of patients with $P_{N a}$ concentrations lower than $135 \mathrm{mmol} / \mathrm{L}$ was similar in both groups at the $4^{\text {th }}(46.2 \% ; 38.5 \%), 8^{\text {th }}(40 \% ; 53.8 \%), 16^{\text {th }}$ $(53.8 \% ; 38.5 \%)$ and 24 th $(0 \%)$ hours after diagnosis $(p>0.05)$. A $\mathrm{P}_{\mathrm{Na}}$ concentration higher than $145 \mathrm{mmol} / \mathrm{L}$ was detected in only one patient of each group at the $24^{\text {th }}$ hour after diagnosis ( $p>0.05)$. The course of $P_{\text {Nacorr }}$ in our patients is shown in Figure 4 . The difference between the groups regarding $P_{\text {Nacorr }}$ was not statistically significant at diagnosis and during follow-up ( $p=0.74$ ) (Table 2). The ratio of patients with a $P_{\text {Nacorr }}$ concentration lower than $135 \mathrm{mmol} / \mathrm{L}$ was also similar in both groups ( $p>0.05)$.

The course of serum potassium levels in our patients is shown in Table 2. There was no hypokalemia either in the beginning or during the follow-up in either group. $\mathrm{pH}$, anion

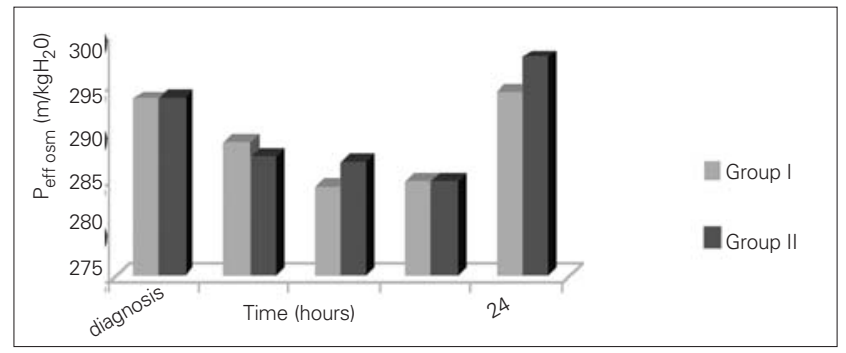

Figure 2. Time courses for $P_{\text {eff osm }}$ from the start of therapy up to 24 hours of therapy

$P_{\text {eff osm }} \mathrm{mOsm} / \mathrm{kgH}_{2} \mathrm{O}$

Table 2. The $\mathrm{P}_{\mathrm{Na}}, \mathrm{P}_{\mathrm{Nacorr}}, \mathrm{K}^{+}, \mathrm{pH}, \mathrm{HCO}_{3}, \mathrm{pCO}_{2}$, anion gap in the two groups at diagnosis and at the $4^{\text {th }}, 8^{\text {th }}, 16^{\text {th }}$ and $24^{\text {th }}$ hour after diagnosis

\begin{tabular}{|c|c|c|c|c|c|c|c|c|c|c|c|}
\hline \multirow[b]{2}{*}{ Time } & \multirow[b]{2}{*}{ Diagnosis } & \multirow[b]{2}{*}{$4^{\text {th }}$ hour } & \multirow{2}{*}{$\begin{array}{l}\text { GROUP I } \\
8^{\text {th }} \text { hour }\end{array}$} & \multirow[b]{2}{*}{$16^{\text {th }}$ hour } & \multirow[b]{2}{*}{$24^{\text {th }}$ hour } & \multirow[b]{2}{*}{ Diagnosis } & \multicolumn{2}{|c|}{ GROUP II } & \multirow[b]{2}{*}{$16^{\text {th }}$ hour } & \multirow[b]{2}{*}{ 24th hour } & \multirow[b]{2}{*}{ p-value } \\
\hline & & & & & & & $4^{\text {th }}$ hour & $8^{\text {th }}$ hour & & & \\
\hline $\mathrm{P}_{\mathrm{Na}}(\mathrm{mEq} / \mathrm{L})$ & $132.2 \pm 7.4$ & $136.0 \pm 5.4$ & $134.2 \pm 4.2$ & $134.5 \pm 2.5$ & $140.1 \pm 2.0$ & $130.5 \pm 5.5$ & $135.6 \pm 4.1$ & $136.0 \pm 5.7$ & $134.9 \pm 4.1$ & $141.1 \pm 4.1$ & 0.4 \\
\hline $\mathrm{P}_{\text {Nacorr }}(\mathrm{mEq} / \mathrm{L})$ & $138.9 \pm 4.7$ & $139.2 \pm 4.7$ & $137.1 \pm 4.3$ & $137.4 \pm 2.6$ & $137.8 \pm 2.1$ & $138.2 \pm 5.5$ & $138.6 \pm 5$ & $138.6 \pm 5.6$ & $137.6 \pm 3.9$ & $138.4 \pm 4.0$ & 0.7 \\
\hline $\mathrm{K}^{+}(\mathrm{mEq} / \mathrm{L})$ & $4.4 \pm 0.4$ & $4.2 \pm 0.4$ & $4.2 \pm 0.3$ & $4.1 \pm 0.4$ & $3.9 \pm 0.4$ & $4.7 \pm 0.4$ & $4.4 \pm 0.4$ & $4.2 \pm 0.4$ & $40 \pm 0.6$ & $4.1 \pm 0.5$ & 0.5 \\
\hline $\mathrm{pH}$ & $7.1 \pm 0.2$ & $7.2 \pm 0.1$ & $7.24 \pm 0.1$ & $7.3 \pm 1.0$ & $7.4 \pm 1.0$ & $7.2 \pm 0.1$ & $7.2 \pm 0.1$ & $7.3 \pm 0.1$ & $7.3 \pm 0.8$ & $7.4 \pm 0.8$ & 0.1 \\
\hline $\mathrm{HCO}_{3}(\mathrm{mEq} / \mathrm{L})$ & $5.3 \pm 3.7$ & $6.9 \pm 4.4$ & $8.4 \pm 4.0$ & $10.9 \pm 4.6$ & $14.8 \pm 6.8$ & $6.6 \pm 4.2$ & $8.1 \pm 5.3$ & $10.1 \pm 4.1$ & $11.2 \pm 3.9$ & $15.0 \pm 5.0$ & 0.9 \\
\hline $\mathrm{pCO}_{2}$ & $14.3 \pm 5.2$ & $15.6 \pm 6.0$ & $17.8 \pm 6.0$ & $21.0 \pm 5.5$ & $23.2 \pm 6.5$ & $15.2 \pm 5.3$ & $15.8 \pm 6.4$ & $18.6 \pm 6.6$ & $20.6 \pm 5.1$ & $24.4 \pm 6.4$ & 0.8 \\
\hline Anion gap & $30.6 \pm 3.6$ & $25.7 \pm 3.9$ & $24.0 \pm 4.2$ & $20.5 \pm 4.4$ & $20.1 \pm 3.7$ & $33.4 \pm 10.8$ & $24.8 \pm 5.7$ & $21.9 \pm 3.7$ & $18.9 \pm 4$ & $18 \pm 3.9$ & 0.8 \\
\hline
\end{tabular}


gap, $\mathrm{pCO}_{2}$ and $\mathrm{HCO}_{3}$ levels were also similar between Group I and Group II at diagnosis and at follow-up (Table 2). Anion gap dropped below $20 \mathrm{mEq} / \mathrm{L}$ at the 16th hour in both groups. The duration of a low pH (>7.3) in Group II was shorter than in Group I, but this was not statistically significant $(13.23 \pm 10.11$ hours in Group II, 20.47 \pm 21.76 hours in Group I) ( $p=0.65)$.

\section{Discussion}

In most countries, treatment of DKA follows standard protocols. In spite of meticulous treatment, a few children develop complications, of which CE is the most dreaded. CE typically occurs 4-12 hours after the initiation of treatment for DKA, but may develop at any time during treatment $(8,9)$. The cause or causes of CE remain unknown. The use of hypotonic fluids during resuscitation has been suggested as a cause $(10,11)$, as have reductions in $\mathrm{P}_{\mathrm{Na}}$ concentration $(10,11,12)$ and rapid changes in plasma osmolality $(13,14)$. In the light of current knowledge, hyponatremia should be avoided in children with DKA $(15,16)$. Rother et al $(17)$ investigated whether rehydration of young patients with DKA by use of a solution with $75 \mathrm{mmol} / \mathrm{L}$ of $\mathrm{Na}$ would be associated with a decline in serum concentrations and they found that such rehydration did not lead to decline in the uncorrected serum $\mathrm{Na}$ level. There is still insufficient evidence correlating the $\mathrm{Na}$ concentration in the rehydration solutions with the $\mathrm{P}_{\mathrm{Na}}$ levels during treatment $(2,18)$. A tendency to increase $\mathrm{Na}$ levels during rehydration has been associated with a favorable outcome and lesser incidence of CE. However, an important concern regarding the use of isotonic instead of hypotonic solutions for rehydration is the risk of triggering hypernatremia $(9,19,20)$. To our knowledge, there is only one reported study comparing hypotonic and isotonic solutions in DKA treatment. The results of this study have suggested that the amount of $\mathrm{Na}$ in rehydration fluids is a relevant and independent factor that favors the acquisition of a positive tendency of natremia (21). These authors have stated that a higher $\mathrm{P}_{\mathrm{Na}}$ level is reached

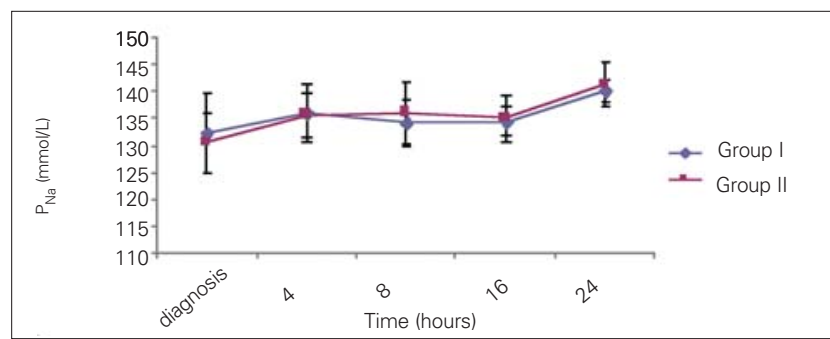

Figure 3. Time courses for $\mathrm{P}_{\mathrm{Na}}$ from the start of therapy up to 24 hours of therapy

$\mathrm{P}_{\mathrm{Na}}$ (measured sodium): $\mathrm{mmol} / \mathrm{L}$ with the use of an isotonic perfusate during rehydration than that achieved with a perfusate with a $\mathrm{Na}$ content in a lower range as recommended by international guidelines $(2,3,4)$.

In contrast to the results reported by Toledo et al (21), in our study, the course of $P_{\mathrm{Na}}, P_{\mathrm{Nacorr}}$ and $\mathrm{P}_{\text {eff osm }}$ at follow-up was not found to show any difference between patients receiving rehydration solutions containing 75 $\mathrm{mEq} / \mathrm{L}$ and $100 \mathrm{mEq} / \mathrm{L}$ of $\mathrm{Na}$. Also in contrast to the results reported by these same authors, higher $\mathrm{Na}$ levels or hypernatremia were not observed in the patients receiving anisotonic solution. The ratio of patients with $P_{\mathrm{Na}}$ and $\mathrm{P}_{\text {Nacorr }}$ concentrations greater than $135 \mathrm{mEq} / \mathrm{L}$ during the follow-up were similar and, $\mathrm{P}_{\mathrm{Na}}$ and $\mathrm{P}_{\mathrm{Nacorr}}$ values did not drop lower than diagnosis levels in both groups.

In DKA, the hyperglycemia should be reduced gradually at a rate of 50 to $100 \mathrm{mg} / \mathrm{hr}$. Early switching to a dextrosecontaining solution, at a blood glucose level of about 250 $\mathrm{mg} / \mathrm{dL}$, helps to avoid rapid fluctuations in osmolality (22). In our treatment protocol, to obtain a $0.45 \%$ saline solution, we added $5 \%$ dextrose to the IV fluid after one-hour rehydration. We think that this prevents fluctuations in plasma osmolality and plays a major role in protecting from CE. However, there is a need for further studies to clarify the efficiency of this regimen in protecting from CE.

Another important aspect is the correlation between $\mathrm{Na}$ administration and time needed to normalize acidosis. Several studies have suggested that the use of fluids with higher Na content would more rapidly correct acidosis (23). The duration of $\mathrm{pH}<7.3$ in Group II was shorter than that in Group I but statistically not significant. In our study, the use of an isotonic solution did not create a difference in anion gap, $\mathrm{HCO}_{3}$ or $\mathrm{pCO}_{2}$ levels. However, longer intravenous insulin duration and delay in passage to subcutaneous insulin treatment might be due to variable individual responses.

We conclude that the efficiency of rehydration fluids with a $\mathrm{Na}$ concentration of 75 or $100 \mathrm{mmol} / \mathrm{L}$ in children with DKA did not differ the course of $\mathrm{P}_{\mathrm{Na}}, \mathrm{P}_{\mathrm{Nacorr}}$ and

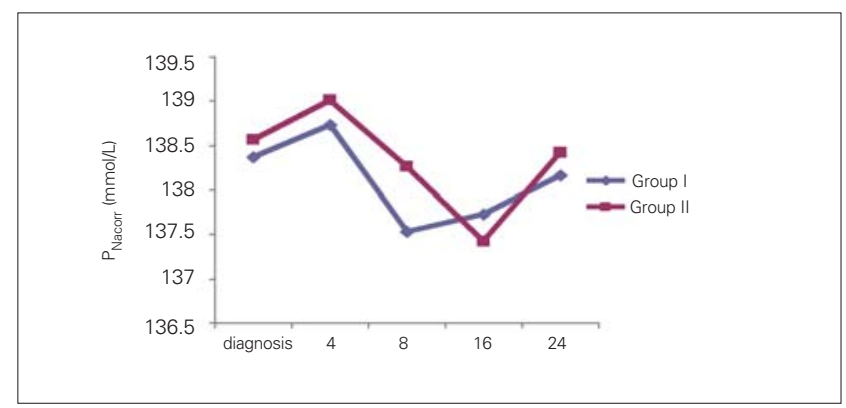

Figure 4. Time courses for $P_{\text {Nacorr }}$ from the start of therapy up to 24 hours of therapy

$\mathrm{P}_{\text {Nacorr }}$ (corrected sodium): $\mathrm{mmol} / \mathrm{L}$ 
Peff osm. This is the second trial that investigated the comparative efficiency of IV solutions with 75 and 100 $\mathrm{mEq} / \mathrm{L} \mathrm{Na}$ concentrations in the treatment of DKA. Thus, although this study may serve to fill a gap in this subject, it had some limitations. Firstly, we used a small sample size and retrospective design and, secondly, we did not observe any patient who developed CE in our sample. Therefore, we believe that it will be logical to prospectively investigate the fluid concentrations used in the treatment of DKA patients who develop CE and their effect, if any, on the development of this condition.

\section{References}

1. Edge JA, Hawkins MM, Winter DL, Dimger DB. The risk and outcome of cerebral edema developing during diabetic ketoacidosis. Arch Dis Child 2001;85:16-22.

2. Dunger DB, Sperling MA, Acerini CL, Bohn GJ, Daneman D, Dane TP, Glaser NS, Hanas R, Hintz RL, Levitsky LL, Savage MO, Tasker RC, Wolfsdorf JI. European Society for Paediatric Endocrinology/Lawson Wilkins Pediatric Endocrine Society Consensus Statement on Diabetic Ketoacidosis in Children and Adolescents. Pediatrics 2004;113:133-140.

3. Wolfsdorf J, Craig ME, Daneman D, Dunger D, Edge J, Lee WR, Rosenbloom A, Sperling MA, Hanas R. International Society for Pediatric and Adolescent Diabetes. Diabetic ketoacidosis. Pediatr Diabetes 2007;8:28-42.

4. Sherry $\mathrm{Na}$, Levitsky LL. Management of diabetic ketoacidosis in children and adolescents. Pediatr Drugs 2008;10:209-215.

5. Rewers M, Pihoker C, Donaghue K, Hanas R, Swift $P$, Klingensmith GJ. ISPAD Clinical Practice Consensus Guidelines 2009 Compendium. Assessment and monitoring of glycemic control in children and adolescents with diabetes. Pediatr Diabetes 2009;10:71-81.

6. Halperin ML, Goldstein MB. Fluid, electrolyte, and acid-base physiology. $3^{\text {rd }}$ ed. Philadelphia: Saunders; 1999.

7. Katz MA. Hyperglycemia-induced hyponatremia-calculation of expected serum sodium depression. New Engl J Med 1973;289:843-844.

8. Edge JA. Cerebral oedema during treatment of diabetic ketoacidosis: are we any nearer finding a cause? Diabetes Metab Res Rev 2000;16:316-324.

9. Glaser N, Barnett P, McCaslin I, Nelson D, Trainor J, Louie J, Kaufman F, Quayle K, Roback M, Malley R, Kuppermann $\mathrm{N}$. for the Pediatric Emergency Medicine Collaborative Research Committee of the American Academy of
Pediatrics. Risk factors for cerebral edema in children with diabetic ketoacidosis. N Engl J Med 2001;344:264-269.

10. Harris GD, Fiordalisi I, Haris WL, Mosovich LL, Finberg L. Minimizing the risk of brain herniation during treatment of diabetic ketoacidemia: a retrospective and prospective study. J Pediatr 1990;117:22-31.

11. Harris GA, Fiordalisi I. Physiologic management of diabetic ketoacidemia. A 5-year prospective pediatric experience in 231 episodes. Arch Pediatr Adolesc Med 1994;148: 1046-1052.

12. Hale PM, Rezvani I, Braunstein AW, Lipmn TH, Martinez N, Garibaldi L. Factors predicting cerebral edema in young children with diabetic ketoacidosis and new onset type 1 diabetes. Acta Paediatr 1997;86:626-631.

13. Bello Fa, Sotos JF. Cerebral oedema in diabetic ketoacidosis in children. Lancet 1990;336:364.

14. Durr JA, Hoffman WH, Sklar AH, el Gammal T, Steinhart CM. Correlates of brain edema in uncontrolled IDDM. Diabetes 1992;41:627-632.

15. Wolfsdorf J, Glaser N, Sperling M. American Diabetes Association. Diabetic ketoacidosis in infants, children and adolescents: a consensus statement from the American Diabetes Association. Diabetes Care 2006;29:1150-1159.

16. Piva JP, Czepielewski M, Garcia PC, Machado D. Current perspectives for treating children with dibetic ketoacidosis. J Pediatr (Rio J) 2007;83:119-127.

17. Rother KI, Schwenk WF $2^{\text {nd }}$. Effect of rehydrationfluid with $75 \mathrm{mmol} / \mathrm{L}$ of sodium on serum sodium concentration and serum osmolality in young patients with diabetic ketoacidosis. Mayo Clin Proc 1994;69:1149-1153.

18. Brown TB. Cerebral edema in childhood diabetic ketoacidosis: Is treatment a factor? Emerg Med J 2004;21:141-144.

19. Hoorn EJ, Carlotti AP, Costa L, MacMahon B, Bohn G, Zietse R, Halperin ML, Bohn D. Preventing a drop in effective plasma osmolality to minimize the likelihood of cerebral edema during treatmentof children with diabetic ketoacidosis. J Pediatr 2007;150:467-473.

20. Harris GD, Fiordalisi I, Yu C. Maintaining normal intracranial pressure in a rabbit model during treatment of severe diabetic ketoacidemia. Life Sci 1996;59:1695-1672.

21. Toledo JD, Modesto V, Peinador M, Alvarez P, Lopez-Prats $\mathrm{JL}$, Sanchis R, Vento M. Sodium concentration in rehydration fluids for children with ketoacidotic diabetes: Effect on serum sodium concentration. J Pediatr 2009;154:895-900.

22. Shastry RM, Bhatia V. Cerebral edema in diabetic ketoacidosis. Indian Pediatr 2006;43:701-708.

23. Fenler El, White PC. Improving management of diabetic ketoacidosis in children. Pediatrics 2001;108:735-740. 